KATRI LASSILA

\title{
Mikko Haiko ja elämä maaseudulla
}

DOI: https://doi.org/10.51807/maaseutututkimus.112224

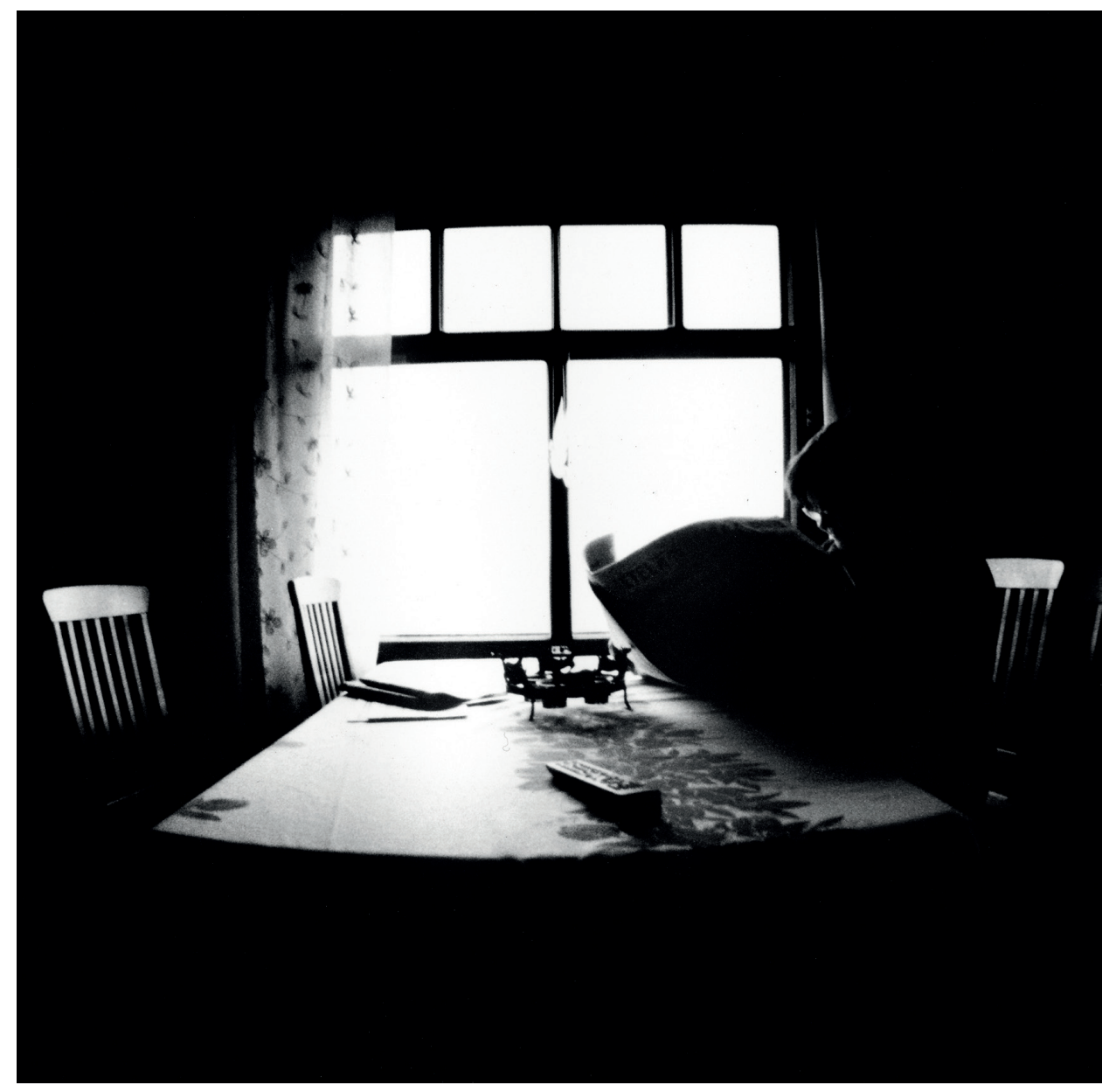

Mikko Haiko: Irja lukee lehteä. 2007-2012. 
$\mathrm{V}$ alokuvataiteilija Mikko Haiko (s. 1984) käsittelee tuotannossaan maaseutua tiuhaan. Voi jopa sanoa, että Haikon taiteen temaattisena selkärankana on maaseutu ja elämä maaseudulla.

"Olen kotoisin Lemiltä, Etelä-Karjalasta. Lapsuuteni maisema oli peltoa, metsää, suota, ojia, lampia, järviä, mäkiä, hiekkatietä ja maatilojen pihapiirejä. Olen opiskellut valokuvaa Aalto-yliopiston taiteiden ja suunnittelun korkeakoulussa. Projektini ovat usein liittyneet syrjäseutujen kuvaamiseen. Minua kiinnostaa paikan ja ihmisen suhde, se miten paikka koetaan ja miten ympäristö virtaa ihmisen läpi.

Valokuvauksessa kiinnostaa sen ready-made-luonne: Valokuva alleviivaa todellisuudesta palasen ja nostaa sen tarkasteltavaksi. Itselleni se on myös hyvin intuitiivinen väline. Maailma on täynnä puhuttelevia peilejä - hetkiä, jotka haluan ikuistaa valokuviksi - ja joiden ottamiseen en usein löydä järjellistä selitystä. Se on kiehtovaa.

Maaseudussa minua kiinnostaa kuvauskohteena sen yksinkertaisuus. Huomaan kuvattavia asioita helpommin, kun olen maalla. Ympärillä on tilaa. Urbaanissa ympäristössä päässäni surisee. Monissa projekteissani maaseutu on myös ikään kuin sattumalta toiminut projektini "raamina", olen esimerkiksi tutkinut kasvuun ja identiteetin kehittymiseen liittyviä teemoja ja kuvannut siksi synnyinseutuani ja se sattuu olemaan maalaiskylä.

Olen pohtinut aiheeni yhteydessä esimerkiksi ylisukupolvista maisemaa ja sielunmaisemaa. Millainen tämä maaperä on, hapekas vai hapeton ja miten maaperää voisi parantaa? Suunnittelen tulevaisuudessa pitkää retkeä vanhoihin kuva-arkistoihini. Yleensä sitä kautta löytyy myös jotain aivan uudenlaista kuvattavaa." 


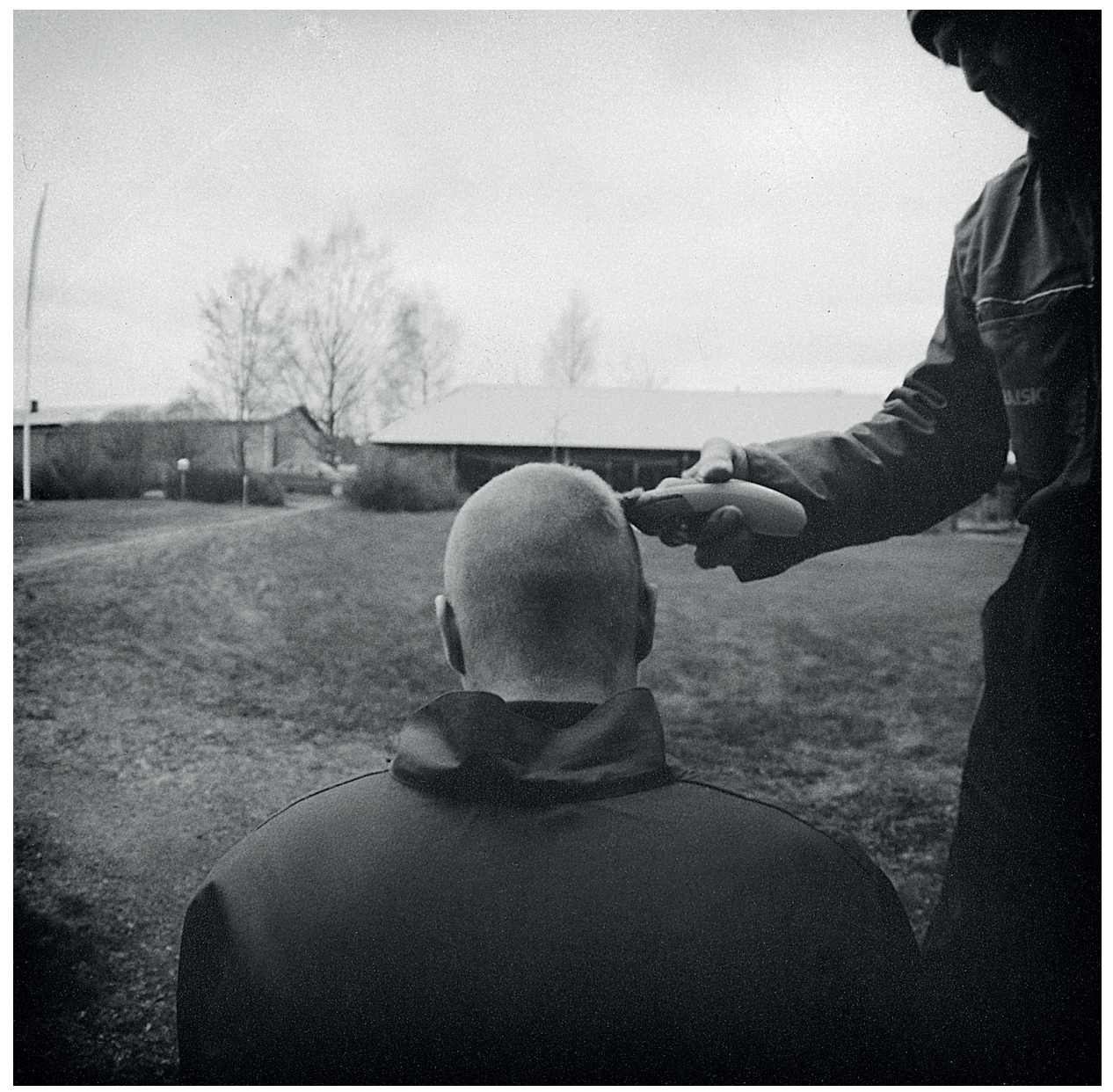

Mikko Haiko: Hiustenleikkuu. 2007-2012. 


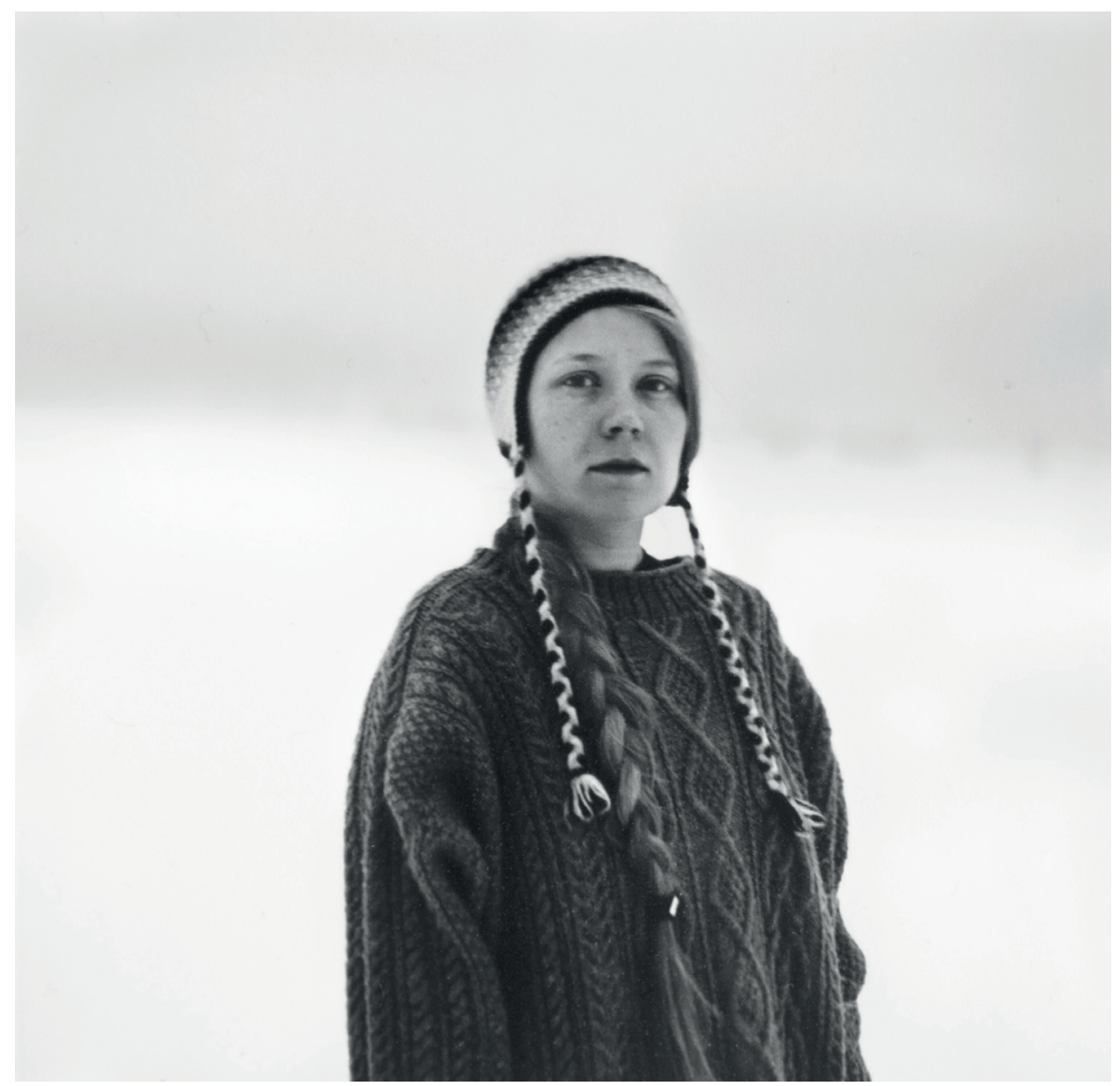

Mikko Haiko: Helinä. 2007-2012. 


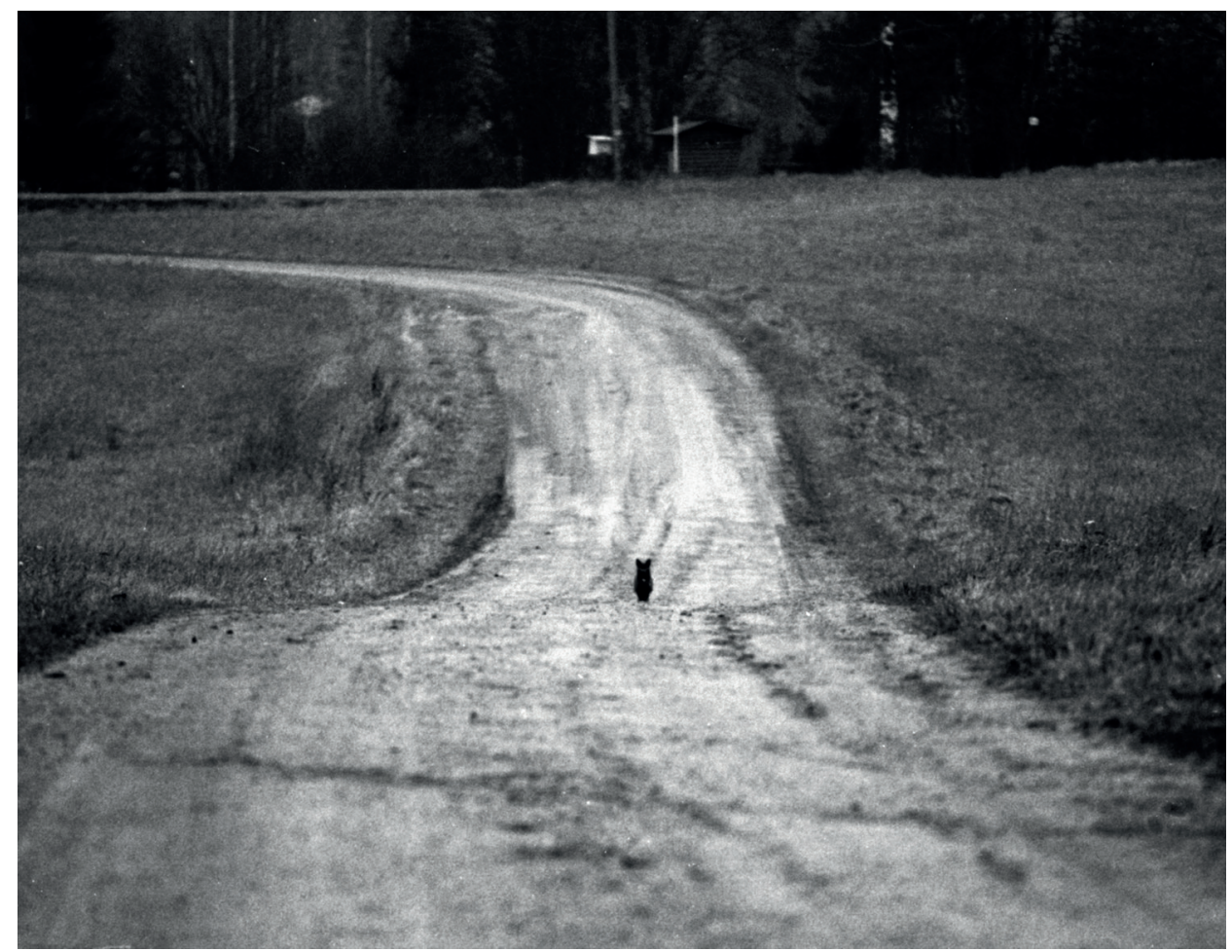

Mikko Haiko: Kissa Nisola Lemi 2007-2012. 


\section{MAASEUTUKUVA}

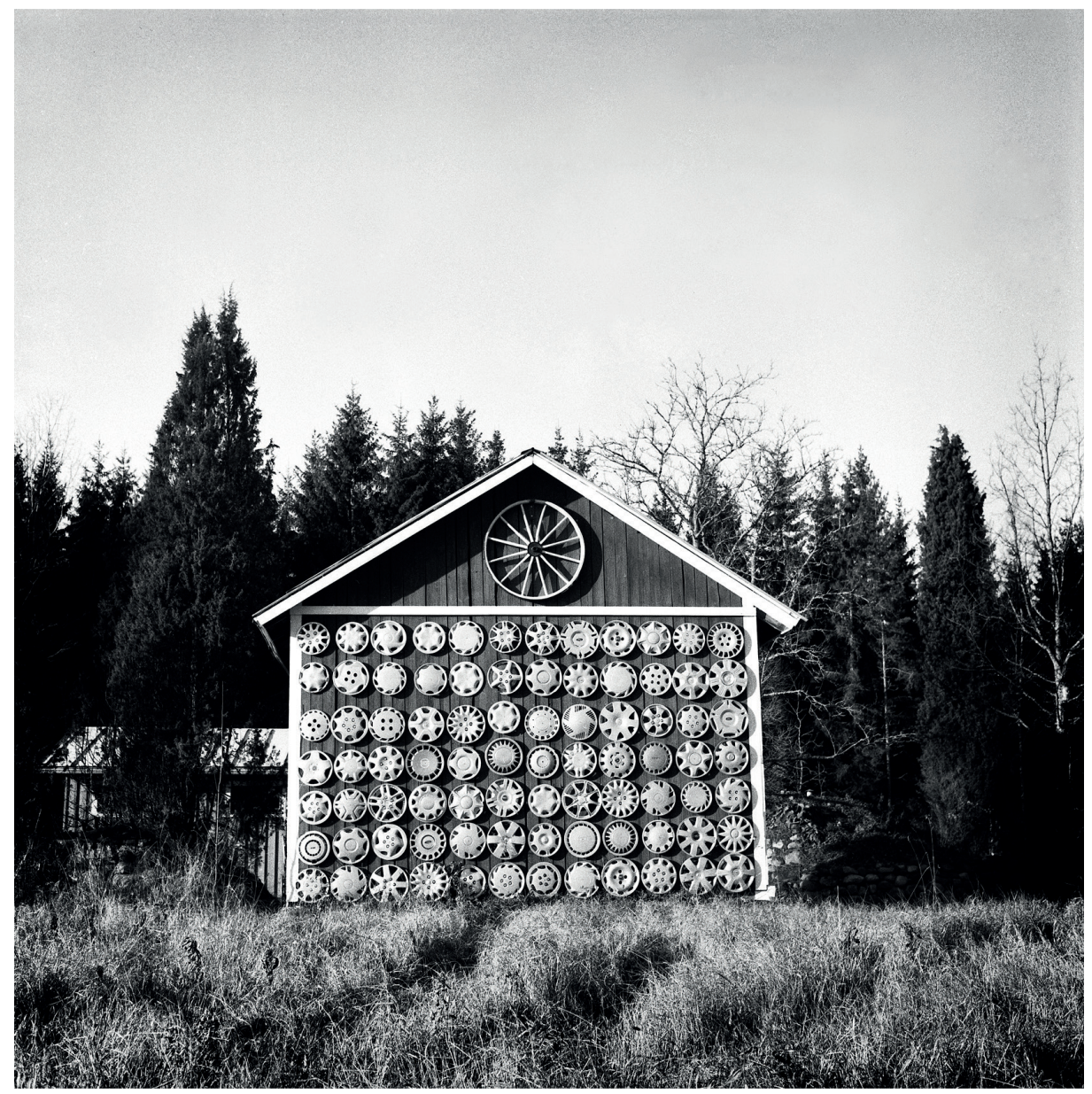

Mikko Haiko: Lato. 2007-2012. 


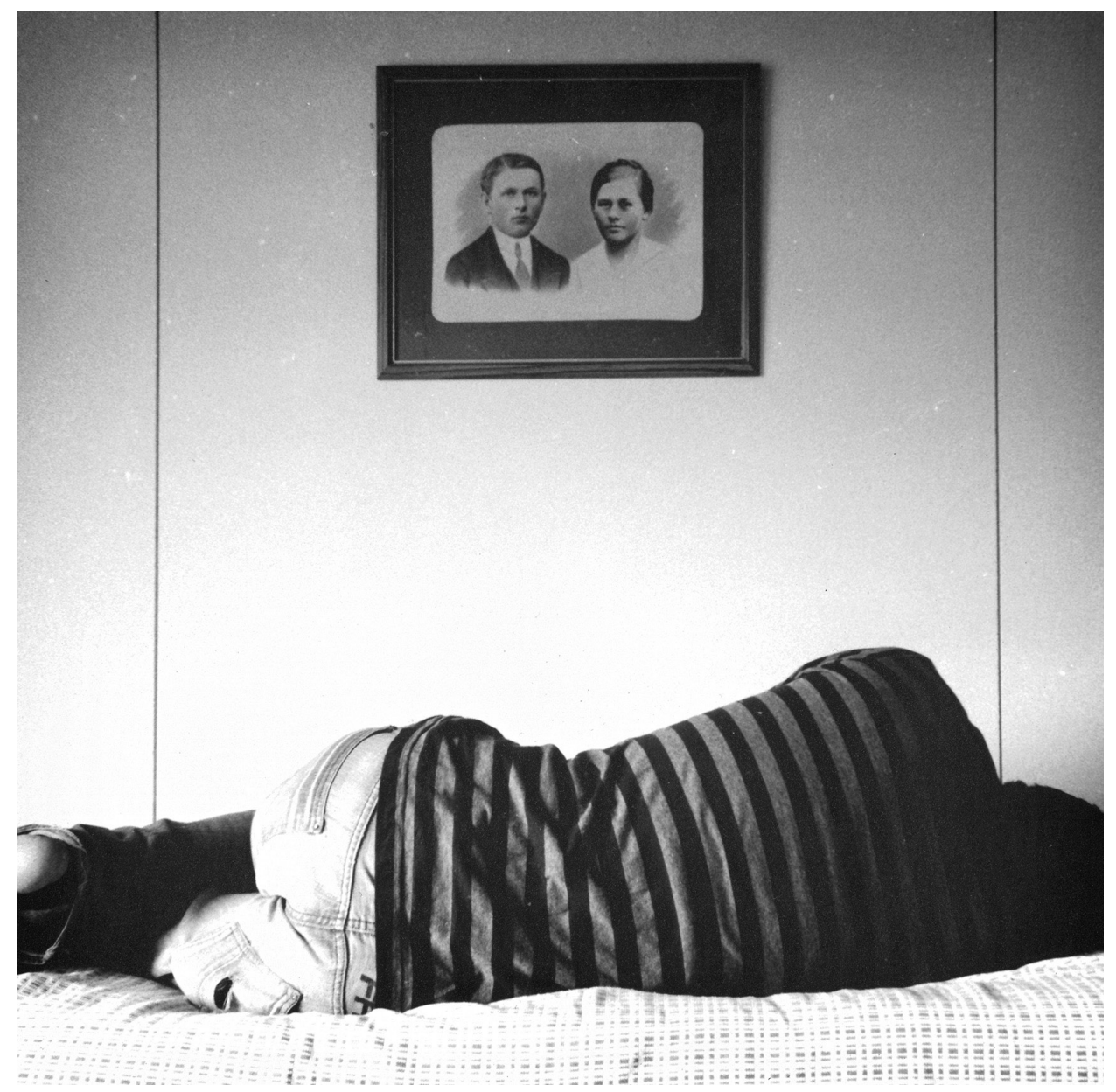

Mikko Haiko: Omakuva. 2007-2012. 